\title{
Treatment of Bell Palsy using Facial Exercises in Primary Health Care: A Case Report
}

\begin{abstract}
Andrezza Maria Côrtes Thomé ${ }^{1}$, Carla Monteiro de Souza ${ }^{2}$, Larissa Alexsandra da Silva Neto Trajano ${ }^{3}$, Adenilson de Souza da Fonseca ${ }^{4}$, Fernando Peribanez Lacerda ${ }^{4}$, Carlos Eduardo Cardoso ${ }^{5}$, Marco Aurélio dos Santos Silva ${ }^{5}$, Marco Orsini ${ }^{* 5,6}$ and Eduardo Tavares Lima Trajano ${ }^{5}$
\end{abstract}

${ }^{1}$ Departamento de Biofísica e Biometria, Universidade do Estado do Rio de Janeiro, Brazil

${ }^{2}$ Prefeitura Municipal de Quatis, Rua Ana Ferreira de Oliveira, Brazil

${ }^{3}$ Mestrado Profissional em Diagnóstico Clínico Laboratorial, Em Medicina Veterinária/ Universidade Severino Sombra, Brazil

${ }^{4}$ Departamento de Biofísica e Biometria, Universidade do Estado do Rio de Janeiro, Brazil

${ }^{5}$ Mestrado Profissional em Ciências Aplicadas em Saúde, Universidade Severino Sombra, Brazil

${ }^{6}$ Mestrado e Doutorado em Ciências da Reabilitação - UNISUAM, Brasil

Received: March 31, 2018; Published: April 11, 2018

*Corresponding author: Marco Orsini, Mestrado Profissional em Ciências Aplicadas em Saúde, Universidade Severino Sombra, Avenida Expedicionário Oswaldo de Almeida Ramos, 280, Centro, Vassouras, 277000000, Mestrado e Doutorado em Ciências da Reabilitação - UNISUAM, Bonsucesso, Rio de Janeiro, Brazil, Email: orsinimarco@hotmail.com

Abstract

In this case report, a patient with Bell palsy received treatment with facial exercises and lubricating drops, A complete recovery was achieved four weeks after presentation. There were no sequelae.

Keywords: Bell Paralysis; Facial Exercises

\section{Introduction}

Sir Charles Bell described the anatomy of the facial nerve and its association with unilateral facial paralysis in 1821. Since then, idiopathic facial paralysis has been termed Bell's palsy. Bell's palsy describes an acute, unilateral facial paralysis [1]. The annual incidence rate is estimated to be between 13 and 53 cases per 100,000 populations [2]. This disease affects approximately 1 in 65 people in a lifetime. Incidence peaks between the ages of 15-45 years [3]. The diagnosis of Bell palsy is made clinically. This entity is a clinical diagnosis after exclusion of the other etiologies of facial paralysis through an astute patient history, physical examination, and laboratory or imaging studies if necessary [4]. Face to face contact is an essential component of human interaction. Facial nerve palsy is devastating and, without appropriate therapy, may result in permanent disfigurement [3]. Consequently, the facial paralysis can have a significant negative impact on one's psychosocial well-being. Identification and management of patients to optimize return of facial function is crucial [1].

\section{Case Report}

A 39-year-old male was diagnosed with Bell palsy after other reasons for facial paresis were excluded, and she received treatment within 5 days after symptom onset. Patient present signs of peripheral facial nerve palsy include loss of facial tone with obliteration of the naso-labial fold, inability to raise the eyebrows and wrinkle the forehead, smile, open or draw the corner of the mouth, and completely close the eye on the affected side. Patient mentioned that he lose the ability to control their lips and mouth, thereby affecting their speech as well as their ability to eat and drink appropriately, ability to appropriately handle a food bolus, as well as saliva, thereby resulting in drooling or biting their own buccal mucosa and ability to express themselves, such as with smiling. $\mathrm{He}$ further includes dryness of eye. The House-Brackman grading score (grade I = normal facial function, grade VI = total paralysis) is used in clinical practice to describe patient's facial dysfunction, facial weakness was assessed as grade III at onset, involving complete closure maximal effort of the eye lid. 
A combination of photographs can help to monitor the extent of facial paralysis; photograph views that were taken include frontal view with brow elevation, eye closure and smiling showing one's teeth (Figure 1). Treatment was made by multi professional healthcare team of Primary Health Care in Quatis, Brazil. Doctor, physiotherapist and nurse evaluated the patient together. Then, lubricating drops were prescribed by doctor and facial exercises by physiotherapist. Facial exercises be performed while standing in front of a mirror and include trying to raise the eyebrows, opening and closing the eyes, blowing, and whistling, 5 times each, three times per day. A complete recovery was achieved four weeks after presentation. There were no sequelae.

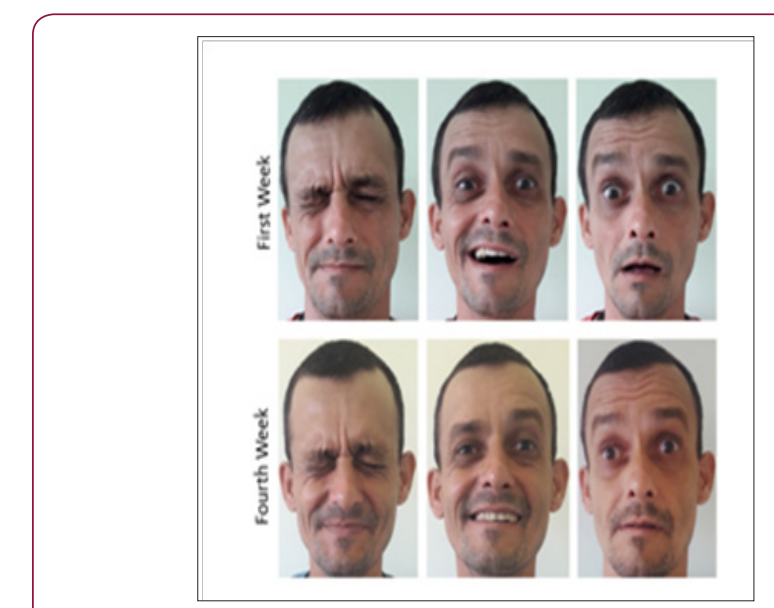

Figure 1: Facial function after four weeks of treatment.

\section{Discussion}

Most patients (85\%) will have a partial recovery within 3-4 weeks and complete recovery within 6 months [3]. However, only $61 \%$ of patients with complete paralysis have complete recovery. Of the patients who do not recover, sequela was slight in $12 \%$ of patients, mild in 13\%, and severe in $4 \%$ [1]. The prognosis for Bell palsy, even if left untreated, is good for most patients. However, about $30 \%$ of those who are untreated will have a poor recovery, with continuing facial disfigurement, psychological difficulties and facial pain [4]. When suffering from a single-sided facial palsy there are many problems arising for the patient to confront. Not only is there the cosmetic disfigurement, but also difficulties to eat, swallow, talk, close the eye with continuous tearing, pain, synkinesis (involuntary muscle movements), muscle atrophy with contractures, reduction of taste, and hearing problems [5]. For many years, Bell palsy was treated with a combination of corticosteroids and antivirals [3]. Treatment with steroids improves the rate of recovery to greater than $90 \%$ segment.

The late phase of treatment is directed toward treating any residual facial movement deficit, and address in synkinesis, facial contractures, or autonomic dysfunction such as crocodile tears or hemi facial spasm [1]. It is important for patients with Bell palsy to have a well trained physiotherapist in the surrounding team to start training early after onset with correct activity. Preferably there is a handout to be given to the patient, at the first meeting, with information about what exercises to do and what not [5]. Physiotherapy in combination with drugs like cortisone and antiviral medication is enhancing HB score according to a recent review, and physiotherapy after a long standing idiopathic facial palsy has been shown to benefit from training with significant increase facial function [6,7]. In this case, patient was treating only facial exercises and lubricating drops. Facial exercises facilitate the return of intended facial movement patterns and eliminating unwanted patterns of facial movement and expression.

\section{Conclusion}

Multi professional healthcare team of Primary Health Care working in medical rehabilitation provides a framework for the multi-professional and multi-disciplinary nature of health promotion. In this case, treatment with orientations about facial exercises shows to decrease recovery time and sequelae in acute Bell palsy.

\section{References}

1. Vakharia K (2016) Bell's palsy. Facial Plast Surg Clin N Am 24(1): 1-10.

2. Rath B, Gidudu JF, Anyoti H, Bollweg B, Caubel P, et al. (2017) Facial nerve palsy including Bell's palsy: Case definitions and guidelines for collection, analysis, and presentation of immunisation safety data. Vaccine 35(15): 1972-1983.

3. Spencer CR, Irving RM (2016) Causes and management of facial nerve palsy. British Journal of Hospital Medicine 77(12).

4. Gagyor I, Madhok V, Sullivan F (2016) A young woman with acute onesided facial paralysis. CMAJ 188(17-18): E531-E532.

5. Hultcrantz M (2015) Rehabilitation of Bells' palsy from a multi-team perspective,. Acta Oto-Laryngologica 136(4): 1-5.

6. Ferreira M, Marques EE, Duarte JA, Santos PC (2015) Physical therapy with drug treatment in Bell palsy: a focused review. Am J Phys Med Rehabil 94(4): 331-340.

7. Watson GJ, Glover S, Allen S, Irving RM (2015) Outcome of facial physiotherapy in patients with prolonged idiopathic facial palsy. J Laryngol Otol 129(4): 348-352.

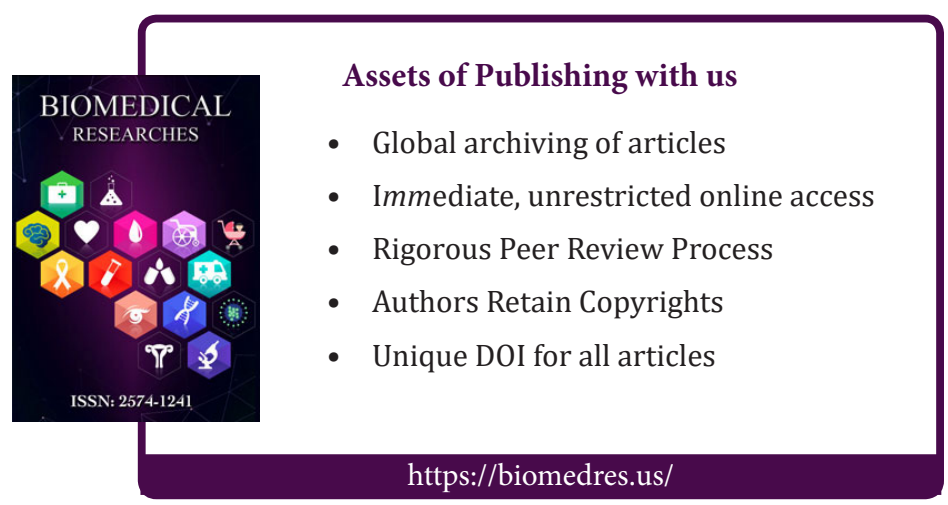

